\title{
LC-MS/MS Method Development and Validation for the Determination of Nifedipine in Human Plasma
}

\author{
Liliya S. Logoyda $1, *$ (iD \\ 1 Pharmaceutical Chemistry Department, Pharmaceutical faculty, I. Horbachevsky Ternopil National Medical University, \\ Ternopil, Ukraine \\ * Correspondence: logojda@tdmu.edu.ua;
}

Scopus Author ID 57188934291

Received: 20.04.2020; Revised: 4.05.2020; Accepted: 5.05.2020; Published: 12.05.2020

\begin{abstract}
The main purpose of this study was to develop a simple, precise, rapid, green and accurate method for the simultaneous quantification of nifedipine in human plasma; The resolution of peaks was best achieved with Intersil ODS gum $\mathrm{C}_{18}(4.6 \times 50 \mathrm{~mm}, 3.5 \mu \mathrm{m})$ column. Samples were chromatographed in a gradient mode (acetonitrile - water - formic acid). The mobile phase was delivered at a flow rate of $0.500 \mathrm{~mL} / \mathrm{min}$ into the mass spectrometer ESI chamber; The total chromatographic run time was 4 minutes. Nifedipine eluted at 3.24 min. A linear response function was established at $1-130 \mathrm{ng} / \mathrm{mL}$ in human plasma. The \% mean recovery in LQC, MQC and HQC was $104.1 \%, 105.0 \%$ and $108.7 \%$. The lowest concentration with the RSD <20\% was taken as LLOQ and was found to be $1.01 \mathrm{ng} / \mathrm{mL}$. The \% accuracy of LLOQ samples prepared with the different biological matrix lots was found $100.5 \%$ for nifedipine, which was found within the range of $80.00-120.00 \%$ for the seven different plasma lots. A rapid method was developed for the determination of nifedipine in human plasma. The method was strictly validated according to the ICH guidelines. Acquired results demonstrate that proposed strategy can be effortlessly and advantageously applied for routine examination of nifedipine in human plasma.
\end{abstract}

Keywords: nifedipine; LC-MS/MS; method development; validation; human plasma.

(C) 2020 by the authors. This article is an open access article distributed under the terms and conditions of the Creative Commons Attribution (CC BY) license (https://creativecommons.org/licenses/by/4.0/).

\section{Introduction}

Bioanalysis is an essential part of drug discovery and development. Bioanalysis is related to the analysis of analytes (drugs, metabolites, biomarkers) in biological samples and it involves several steps from sample collection to sample analysis and data reporting. The first step is sample collection from clinical or preclinical studies; then sending the samples to laboratory for analysis. Second step is sample clean-up (sample preparation) and it is a very important step in bioanalysis. In order to reach reliable results, a robust and stable sample preparation method should be applied. The role of sample preparation is to remove interferences from the sample matrix and improve analytical system performance. Sample preparation is often labor intensive and time consuming. The last step is the sample analysis and detection. For separation and detection, liquid chromatography-tandem mass spectrometry (LC-MS/MS) is a method of choice in bioanalytical laboratories [1-9].

Nifedipine has been formulated as both a long- and short-acting 1,4-dihydropyridine calcium channel blocker. It acts primarily on vascular smooth muscle cells by stabilizing voltage-gated L-type calcium channels in their inactive conformation. By inhibiting the influx of calcium in smooth muscle cells, nifedipine prevents calcium-dependent myocyte contraction 
and vasoconstriction. A second proposed mechanism for the drug's vasodilatory effects involves $\mathrm{pH}$-dependent inhibition of calcium influx via inhibition of smooth muscle carbonic anhydrase. Nifedipine is used to treat hypertension and chronic stable angina. Its structure is shown in Fig. 1. Chemical name of nifedipine is dimethyl 2,6-dimethyl-4-(2-nitrophenyl)-1,4dihydropyridine-3,5-dicarboxylate.<smiles>COC(=O)C1=C(C)NC(C)=C(C(=O)OC)C1c1ccccc1[N+](=O)[O-]</smiles>

Figure 1. Chemical structure of nifedipine.

The State Pharmacopoeia of Ukraine (SPhU) has a monograph on the substance of nifedipine. For identification of the substance of nifedipine, the SPhU offers the determination of melting point, absorption spectrophotometry in the infrared region, TLC (mobile phase ethyl acetate $\mathrm{P}$ - cyclohexane (40:60)) and qualitative reaction of formation of azo dye after the previous restoration of nitro group to amino group, quantitative determination - cerimetry. The United States Pharmacopoeia regulates the definition of nifedipine in substances and tablets. For identification, the definition of absorption spectrophotometry in the infrared region and UV-spectrophotometry is proposed. For quantitative determination of nifedipine in tablets - HPLC/UV method. In accordance with this article, the following chromatographic conditions are used: chromatographic column of category L1 (with fixed phase C18) with size $4.6 \mathrm{~mm} \mathrm{x}$ $250 \mathrm{~mm}$; mobile phase - acetonitrile: methanol: water (25:25:50); solvent - methanol, wavelength $-235 \mathrm{~nm}$, flow rate $-1.0 \mathrm{ml} / \mathrm{min}$. The European Pharmacopoeia has a monograph on the substance of nifedipine. For identification, it is proposed to determine the melting point, absorption spectrophotometry in the infrared region, TLC (mobile phase - a mixture of ethyl acetate $\mathrm{P}$ and cyclohexane $\mathrm{P}(40: 60 \mathrm{~V} / \mathrm{V})$ and qualitative reaction to the primary aromatic amino group - reaction of formation of azo dye (after preliminary reduction of nitro group to amino group). For the quantitative determination of nifedipine - method of cerimetry. In the contemporary literature, few bioanalytical methods were reported for quantification of nifedipine in human plasma [2-6]. Therefore, it was thought desirable to develop a simple, accurate, green, cheap and fast procedure that could be applied for the simultaneous determination of nifedipine in human plasma, this study performed assay validations as per guidelines [7-15]. While this method with validation details was economical and applied for pharmacokinetic studies of nifedipine.

\section{Materials and Methods}

\subsection{Chemicals and reagents.}

Nifedipine (purity $100.0 \%$ ), tolterodine (Internal Standard) (purity $99.9 \%$ ) were purchased from Moehs Catalana, S.L., Spain, Zhejiang Huahai Pharmaceutical Co., Ltd, KHP, EDQM - Council of Europe. HPLC grade acetonitrile and methanol were purchased from CHROMASOLV, HPLC grade formic acid was purchased from Fluka. All other chemicals 
and reagents were of analytical grade. Microcaps ${ }^{\circledR}$ disposable micropipettes $(50 \mu \mathrm{l}$, catalog number: 1-000-0500) were purchased from Drummond Scientific Company, USA. The control human dipotassium ethylenediaminetetraacetic acid ( $\mathrm{K}_{2}$ EDTA) plasma sample was procured from Red Cross Society, Ukraine.

\subsection{Instruments.}

Quantitative analysis of the analytes under investigation was carried out with LCMS/MS system from Exion LC ${ }^{\text {TM }}$ (ABSciex, USA) coupled with an applied Biosystem API4500 triple quadrupole mass spectrometer (ABSciex, Canada) equipped with the positive electrospray ionization using multiple reaction monitoring (MRM) mode. The source dependent parameters maintained for all analytes were: cone gas flow $50 \mathrm{~L} / \mathrm{h}$, desolvation gas flow $800 \mathrm{~L} / \mathrm{h}$, cone voltage $4 \mathrm{KV}$, source temperature $600^{\circ} \mathrm{C}$. The collision of the gas was maintained at 8 psi. Unit tmass resolution was employed and the dwell time was set at $100 \mathrm{~ms}$ All MS/MS parameters were optimized by direct infusion of standards into the MS at a flow rate of $10 \mu \mathrm{L} / \mathrm{min}$. Analyst software Hotfixes version (ABSciex,1.6.3. ${ }^{\circledR}$ ) was used to control all parameters of LC and MS.

\subsection{Liquid chromatographic and mass spectrometric conditions}

Chromatographic separations were performed using Intersil ODS gum $\mathrm{C}_{18}(4.6 \times 50$ $\mathrm{mm}, 3.5 \mu \mathrm{m}$ ) maintained at $30^{\circ} \mathrm{C}$. Samples (injection volume of $30 \mu \mathrm{L}$ ) were separated using a gradient mobile phase consisting of methanol, $0.1 \%$ formic acid, acetonitrile and was delivered at a flow rate of $0.5 \mathrm{~mL} / \mathrm{min}$. Parameters of gradient mode is presented in Table 1 .

Table 1. Parameters of gradient mode.

\begin{tabular}{l|l|l|l}
\multirow{2}{*}{ Time (min) } & \multicolumn{3}{|c}{ Mobile phase } \\
\cline { 2 - 4 } & $\mathbf{0 . 1} \%$ formic acid pH 3.0 & Acetonitrile & Methanol \\
\hline $0-0.5$ & 15 & 80 & 5 \\
\hline $0.5-0.7$ & 80 & 15 & 5 \\
\hline $0.7-3.5$ & 90 & 10 & 0 \\
\hline $3.5-3.7$ & 80 & 15 & 5 \\
\hline $3.7-5.0$ & 15 & 80 & 5
\end{tabular}

\subsection{Standard solutions.}

Nifedipine and IS were weighed accurately into volumetric flasks using an analytical microbalance. Approximately $1 \mathrm{mg} / \mathrm{ml}$ primary stock solutions of nifedipine and $0.5 \mathrm{mg} / \mathrm{ml}$ primary stock solutions of IS solutions were prepared in methanol. The stock solutions were stored at $-20^{\circ} \mathrm{C}$, which was found to be stable for 1 month. The stock solutions of nifedipine were successively diluted with methanol and water to prepare secondary stocks and working solutions. Secondary stock solutions and working solutions were used to prepare calibration curve (CC) and quality control (QC) samples. Working stock solutions were stored at $4{ }^{\circ} \mathrm{C}$ for a week. Working stocks were used to prepare plasma calibration standards. A working IS solution $(20 \mathrm{ng} / \mathrm{ml})$ was prepared in acetonitrile:methanol $(50: 50 \mathrm{v} / \mathrm{v})$. Blank human plasma was screened before spiking to ensure that it was free from endogenous interference at retention times of nifedipine and IS, respectively. Calibration standards' samples (1 - $100 \mathrm{ng} / \mathrm{ml}$ for nifedipine) were prepared by spiking the blank human $\mathrm{K}_{2}$ EDTA plasma with an appropriate concentration of nifedipine.

Samples for the determination of precision and accuracy were prepared by spiking control human plasma in bulk with nifedipine at appropriate concentrations (for nifedipine 3.12 
ng/ml low QC [LQC], $31.5 \mathrm{ng} / \mathrm{ml}$ medium QC [MQC], and $81.5 \mathrm{ng} / \mathrm{ml}$ high QC [HQC] and $120 \mu \mathrm{L}$ plasma aliquots were distributed into different tubes. All the samples were stored at $-80^{\circ} \mathrm{C} \pm 10^{\circ} \mathrm{C}$.

\subsection{Sample preparation.}

A simple protein precipitation extraction method was followed for the extraction of nifedipine at from human plasma. From the deep freezer, the required quantities of CC standards and QC samples were withdrawn. The samples were thawed at room temperature. To an aliquot of $100 \mu \mathrm{l}$ plasma, $20 \mu \mathrm{l}$ of IS was added. To this mixture, $300 \mu \mathrm{l}$ of acetonitrile:methanol $(50: 50 \mathrm{v} / \mathrm{v})$ was added and vortexed for 2 minutes, followed by centrifugation at $6000 \mathrm{rpm}$ for 5 minutes at $4^{\circ} \mathrm{C}$. After centrifugation, approximately $50 \mu \mathrm{l}$ supernatant was aliquoted into, respectively, labeled autosampler vials, which were later placed in the autosampler at $15^{\circ} \mathrm{C} \pm 4^{\circ} \mathrm{C} .10 \mu \mathrm{l}$ of the sample was injected onto LC-MS/MS system for analysis.

\subsection{Method validation.}

A full validation according to the ICH guidelines was performed for the assay in $\mathrm{K}_{2}$ EDTA human plasma [10-18].

\section{Results and Discussion}

In the present study, optimization and critical evaluation of mobile phase composition (gradient), flow rate, and analytical column were important to obtain a good resolution of peaks of interest from the endogenous components, which in turn affect reproducibility and sensitivity of the method [15-18]. The selection of chromatographic conditions for the proposed method was optimized to suit the preclinical pharmacokinetic studies. To ease the sample preparation in microtubes and to reduce the usage of solvent, the plasma volume was kept low. Initial feasibility experiments of various mixture(s) of solvents such as acetonitrile, methanol and formic acid along with altered flow rates (in the range of $0.1-0.6 \mathrm{ml} / \mathrm{min}$ ) were performed to optimize an effective chromatographic resolution of nifedipine and IS. Various analytical columns were tested to obtained good and reproducible responses within short run time. The resolution of peaks was best achieved with Intersil ODS gum $\mathrm{C}_{18}(4.6 \times 50 \mathrm{~mm}, 3.5 \mu \mathrm{m})$ column. Samples were chromatographed in a gradient mode (acetonitrile - water - formic acid). The mobile phase was delivered at a flow rate of $0.500 \mathrm{ml} / \mathrm{min}$ into the mass spectrometer ESI chamber. The injection volume was $30 \mu \mathrm{l}$.

The purpose of sample extraction optimization is mainly to achieve high extraction recovery with negligible or low matrix effects to improve the sensitivity and reliability of LCMS/MS analysis [10-16]. A poor extraction procedure decreases method robustness due to the presence of endogenous interference in the sample extracts, which are not efficiently cleaned up due to poor extraction procedure decreases the method robustness due to the endogenous interference in the sample extracts. With time-saving advantage and simplicity, the protein precipitation extraction method was chosen as an extraction method. The attained LLOQ was sufficient to quantify nifedipine in low-dose pharmacokinetic studies.

Nifedipine eluted at $\sim 3.24$ min. Typical multiple reaction monitoring chromatograms of nifedipine, enalapril and internal standard in dipotassium ethylenediaminetetraacetic acid human blank plasma are shown in Fig. 2. 


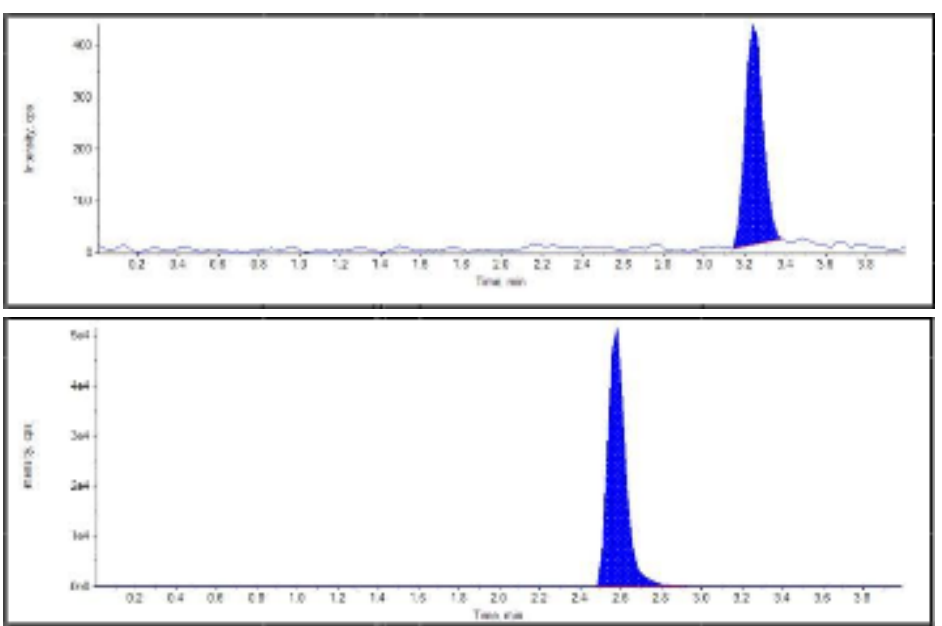

Figure 2. Typical multiple reaction monitoring chromatograms of nifedipine (I) and internal standard (II) in dipotassium ethylenediaminetetraacetic acid human blank plasma.

\subsection{Selectivity.}

The method selectivity was processed using six plasma samples obtained from healthy volunteers. Representative chromatograms clearly indicate the absence of significant interference peaks in human blank plasma spiked with nifedipine at the analytes retention times (Fig. 2). The retention time of human blank plasma spiked with nifedipine was $3.24 \mathrm{~min}$. The absence of interference peaks from endogenous substances indicates that our suggested method is selective for the analytes of interest in real human plasma.

\subsection{Linearity.}

The calibration standard curves had a reliable reproducibility over the standard concentrations across the calibration range. The average regression $(n=3)$ was found to be $>0.995$.

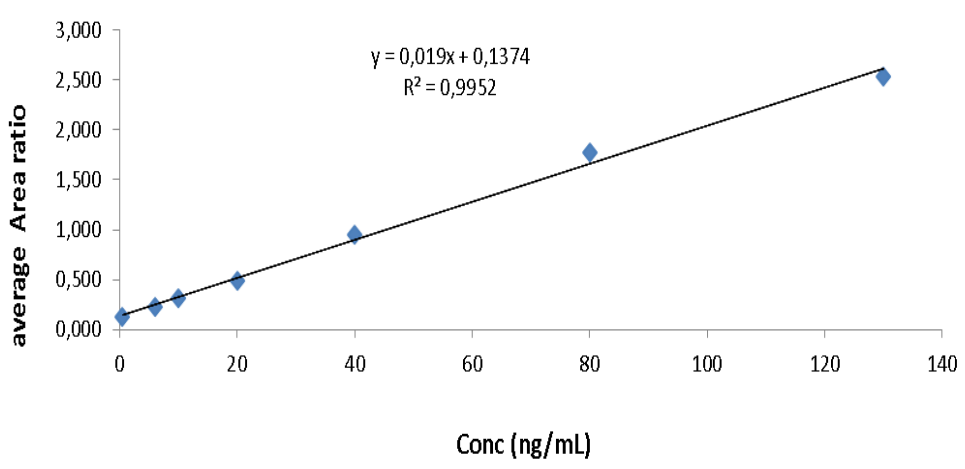

Figure 3. The calibration curve of nifedipine in human plasma

The calibration curve (peak area ratio Vs Concentration) was linear over working range for nifedipine of 1 to $130.00 \mathrm{ng} / \mathrm{ml}$ with 7 point calibration used for quantification by linear regression, shown in Fig. 3. The regression equation for the analysis was $\mathrm{y}=0.019 \mathrm{x}+0.1374$ with coefficient of correction $(\mathrm{r} 2)=0.9952$.

\subsection{Recovery.}

The \% mean recovery in LQC, MQC and $\mathrm{HQC}$ are listed in Table 2. 
Table 2. The \% mean recovery of nifedipine for LQC, MQC and HQC

\begin{tabular}{l|l|l|l} 
No. & LQC & MQC & HQC \\
\hline 1 & 3.13 & 31.3 & 80.2 \\
\hline 2 & 3.29 & 29.8 & 72.5 \\
\hline 3 & 3.04 & 31.2 & 80.2 \\
\hline 4 & 3.22 & 30.5 & 88.0 \\
\hline 5 & 2.94 & 34.9 & 86.9 \\
\hline Mean & 3.12 & 31.5 & 81.5 \\
\hline SD & 0.140 & 1.97 & 6.27 \\
\hline \% CV & 4.5 & 6.3 & 7.7 \\
\hline \% Mean Recovery & 104.1 & 105.0 & 108.7
\end{tabular}

* Abbreviations: Lower quality control (LQC), middle quality control (MQC), higher quality control (HQC)

Each value is represented as a mean \pm SD of 5 observations $(n=5)$, SD: Standard Deviation, RSD: Relative Standard Deviation, \#Acceptance criteria<2.0.

The \% mean recovery for nifedipine in LQC, MQC and HQC was $104.1 \%, 105.0 \%$ and $108.7 \%$ respectively.

\subsection{Intraday (within run) and Inter-day (between run) precision and accuracy.}

The within-run coefficients of variation ranged between $0.331 \%$ and $0.619 \%$. The within-run percentages of nominal concentrations ranged between $98.80 \%$ and $100.63 \%$. The between-run coefficients of variation ranged between $0.332 \%$ and $0.615 \%$. The between-run percentages of nominal concentrations ranged between $98.98 \%$ and $101.71 \%$. The results are presented in Table 3. The assay values on both the occasions (intra- and inter-day) were found to be within the accepted limits.

Table 3. Intra-day and Inter-day precision data.

\begin{tabular}{l|c|c|c|c} 
Day & \multicolumn{2}{|c|}{ Intra-day precision } & \multicolumn{2}{c}{ Inter-day precision } \\
\hline & Mean & RSD \% & Mean & RSD \% \\
\hline 1 & 98.80 & 0.378 & 101.71 & 0.332 \\
\hline 2 & 100.41 & 0.619 & 98.98 & 0.390 \\
\hline 3 & 100.63 & 0.331 & 100.53 & 0.615
\end{tabular}

*Each value is represented as a mean \pm SD of observations, SD: Standard Deviation, RSD: Relative Standard Deviation, \#Acceptance criteria<2.0

\subsection{Matrix effect.}

The lowest concentration with the RSD $<20 \%$ was taken as LLOQ and was found to be $1.01 \mathrm{ng} / \mathrm{ml}$ for nifedipine. The \% accuracy of LLOQ samples prepared with the different biological matrix lots was found $100.5 \%$, which were found within the range of 80.00-120.00 $\%$ for the seven different plasma lots. \% CV for LLOQ samples was observed as $7.4 \%$, which are within $20.00 \%$ of the acceptance criteria. Results are presented in Table 4.

Table 4. Results of matrix effect.

\begin{tabular}{l|l} 
No. & LLQC \\
\hline 1 & 1.04 \\
\hline 2 & 0.950 \\
\hline 3 & 0.906 \\
\hline 4 & 1.08 \\
\hline 5 & 1.05 \\
\hline Mean & 1.01 \\
\hline SD & 0.074 \\
\hline \% CV & 7.4 \\
\hline \% Mean Recovery & 100.5
\end{tabular}

* Abbreviations: Lower limit of quantification (LLOQ)

Each value is represented as a mean \pm SD of 5 observations ( $n=5)$, SD: Standard Deviation, RSD: Relative Standard Deviation, \#Acceptance criteria<2.0. 


\subsection{Stability.}

The predicted concentrations for nifedipine $(3.12 \mathrm{ng} / \mathrm{ml}$ and $81.5 \mathrm{ng} / \mathrm{ml})$ deviated within $\pm 15 \%$ of the fresh sample concentrations in a battery of stability tests namely, in-injector (22 hrs), bench-top ( $7 \mathrm{hrs}$ ), and repeated four freeze/thaw cycles stability. The results were found to be within the assay variability limits during the entire process.

\section{Conclusions}

In summary, a highly sensitive, specific, reproducible, rapid, green and high-throughput LC-MS/MS assay has been developed and validated to quantify nifedipine in human plasma as per the regulatory guidelines. The present method involved a simple precipitation method of sample preparation, which gave consistent and reproducible recoveries. Acquired results demonstrate that proposed strategy can be effortlessly and advantageously applied for routine examination of nifedipine in human plasma. The validity of proposed method supports its use for the routine assay in pharmacokinetic studies or bioequivalence studies and will be useful in therapeutic drug monitoring.

\section{Funding}

This research received no external funding.

\section{Acknowledgments}

The authors declare no acknowledgments.

\section{Conflicts of Interest}

The authors declare no conflict of interest.

\section{References}

1. European Pharmacopoeia. European Pharmacopoeia. $10 \quad$ edn. 2020, https://www.edqm.eu/en/european_pharmacopoeia_10th_edition

2. The State Pharmacopeia of Ukraine in 3 vol. State Enterprise "Ukrainian Scientific Expert Pharmacopoeial Center of the Quality of Medicines" 2nd iss. Kharkiv: State Enterprise "Ukrainian Scientific and Experimental Pharmacopoeial Center for the Quality of Medicinal Products". 2015, 1128.

3. Logoyda, L. Analysis of approaches to the development and validation of the methods of analysis of some active pharmaceutical ingredients from the group of calcium channel blockers in drugs and biological liquids. International Journal of Applied Pharmaceutics 2019, 11, 26-34, https://doi.org/10.22159/ijap.2019v11i3.32498.

4. Logoyda, L.; Abdel-Megied, A.M.; Kondratova, Y.; Trofimenko, O.; Korobko, D.; Dakhym, I. Development and validation of HPLC method for the simultaneous determination of enalapril maleate in present of their impurities: application to tablet analysis. International Journal of Applied Pharmaceutics 2018, 10, 98-102, https://doi.org/10.22159/ijap.2018v10i1.22805.

5. Logoyda, L. Dmytro, K.; Oleksandra, O.; Taras, P.; Mariya, D. A HPLC-MS/MS method development and validation for the simultaneous determination of bisoprolol and enalapril in the present of enalaprilat in human plasma. International Journal of Applied Pharmaceutics 2018, 10, 31-40, https://doi.org/10.22159/ijap.2018v10i2.23195.

6. Logoyda, L.; Mykhalkiv, M.; Polyauk, O.; Zarivna, N.; Soroka, Y., Demydiak, O. Ultra-high-performance liquid chromatography as assay method for the investigation of conditions of captopril extraction by organic solvents. Asian Journal of Pharmaceuticals 2018, 12, http://dx.doi.org/10.22377/ajp.v12i01.2049.

7. Mykhalkiv, M.; Logoyda, L.; Polyauk, O.; Zarivna, N.; Soroka, Y.; Ryabokon, S.; Riabokon, M. HPLC as assay method for the investigation of conditions of bisoprolol extraction by organic solvents. International Journal of Green Pharmacy 2018, 12, 276-9, http://dx.doi.org/10.22377/ijgp.v12i01.1633. 
8. Logoyda, L. Bioanalytical method development and validation from the simultaneous determination of verapamil and enalapril in the present of enalaprilat by HPLC MS/MS. International Journal of Applied Pharmaceutics 2018, 10, 19-27.

9. Logoyda, L. Quantitative determination of amlodipine from Caco-2 cell monolayers by high-performance liquid chromatography-mass spectrometry/mass spectrometry. Asian Journal of Pharmaceutical and Clinical Research 2018, 11, 204-7, https://doi.org/10.22159/ajpcr.2018.v11i6.24971.

10. Kondratova, Y.; Adebayo, T.; Logoyda, L.; Korobko, D.; Berdey, I.; Kuchmerovska, T. Development of the methodology of the chromatographic determination of amlodipine in medicines. Int. J. Res. Ayurveda Pharm. 2016, 7, 32-35, https://doi.org/10.7897/2277-4343.074128.

11. Kondratova, Y.; Logoyda, L.; Voloshko, Y.; Abdel-Megied, A.; Korobko, D.; Soroka, Y. Development and validation of HPLC-DAD method for the determination of bisoprolol in tablet dosage forms. Int J App Pharm. 2017, 9, 54-9, https://doi.org/10.22159/ijap.2017v9i6.21616.

12. Polyauk, O.; Logoyda, L. The investigation of conditions of API from group of calcium channel blockers extraction by organic solvents by using high-performance liquid chromatography as method assay. Asian J Pharm Clinical Res. 2017, 10, 354-356, https://doi.org/10.22159/ajpcr.2017.v10i10.20506.

13. Yuryeva, O.; Kondratova, Y.; Logoyda, L. Development of high-performance liquid chromatography method for simultaneous analysis of amlodipine and valsartan in combined dosage form and in vitro disslotution studies. Asian Journal of Pharmaceutical and Clinical Research. 2018, 11, 200-204, https://doi.org/10.22159/ajpcr.2018.v11i5.24443.

14. Logoyda, L. A high-performance liquid chromatography-mass spectrometry method development for the quantitative determination of enalapril maleate from Caco-2 cell monolayers. Asian Journal of Pharmaceutical and Clinical Research 2018, 11, 89-92, https://doi.org/10.22159/ajpcr.2018.v11i7.25455.

15. Logoyda, L.; Korobko, D. A high-performance liquid chromatography-mass spectrometry/mass spectrometry method development for the quantitative determination of bisoprolol from Caco-2 cell monolayers. Asian Journal of Pharmaceutical and Clinical Research 2018, 11, 386-389, https://doi.org/10.22159/ajpcr.2018.v11i4.24990.

16. Logoyda, L. A HPLC-MS/MS method development and validation for the simultaneous determination of nifedipine and enalapril in human plasma. International Journal of Applied Pharmaceutics 2018, 10, 35-42, https://doi.org/10.22159/ijap.2018v10i4.24528.

17. Logoyda, L. Efficient validated method of HPLC to determine enalapril in combinated dosage form containing enalapril and bisoprolol and in vitro dissolution studies. International Journal of Applied Pharmaceutics 2019, 11, 19-24, https://doi.org/10.22159/ijap.2019v11i4.32584.

18. Logoyda, L. Sergiy, K.; Ahmed, M.A.M.; Igor, Z.; Iryna, D.; Inna, D.; Oleh, N. HPLC method development for the analysis of bisoprolol in combined dosage form containing bisoprolol and enalapril and in vitro dissolution studied. International Journal of Applied Pharmaceutics 2019, 11, 186-194, https://doi.org/10.22159/ijap.2019v11i3.32391. 